\title{
Challenges of one-year longitudinal follow- up of a prospective, observational cohort study using an anonymised database: recommendations for trainee research collaboratives
}

\author{
STARSurg Collaborative
}

\begin{abstract}
Background: Trainee research collaboratives (TRCs) have pioneered high quality, prospective 'snap-shot' surgical cohort studies in the UK. Outcomes After Kidney injury in Surgery (OAKS) was the first TRC cohort study to attempt to collect one-year follow-up data. The aims of this study were to evaluate one-year follow-up and data completion rates, and to identify factors associated with improved follow-up rates.

Methods: In this multicentre study, patients undergoing major gastrointestinal surgery were prospectively identified and followed up at one-year following surgery for six clinical outcomes. The primary outcome for this report was the follow-up rate for mortality at 1 year. The secondary outcome was the data completeness rate in those patients who were followed-up. An electronic survey was disseminated to investigators to identify strategies associated with improved follow-up.

Results: Of the 173 centres that collected baseline data, 126 centres registered to participate in one-year follow-up. Overall 62.3\% (3482/5585) of patients were followed-up at 1 year; in centres registered to collect one-year outcomes, the follow-up rate was $82.6 \%$ (3482/4213). There were no differences in sex, comorbidity, operative urgency, or 7-day postoperative AKI rate between patients who were lost to follow-up and those who were successfully followed-up. In centres registered to collect one-year follow-up outcomes, overall data completeness was $83.1 \%$, with $57.9 \%(73 / 126)$ of centres having $\geq 95 \%$ data completeness. Factors associated with increased likelihood of achieving $\geq 95 \%$ data completeness were total number of patients to be followed-up $(77.4 \%$ in centres with < 15 patients, $59.0 \%$ with 15-29 patients, 51.4\% with 30-59 patients, and 36.8\% with > 60 patients, $p=0.030$ ), and central versus local storage of patient identifiers ( $72.5 \%$ vs $48.0 \%$, respectively, $p=0.006$ ).

Conclusions: TRC methodology can be used to follow-up patients identified in prospective cohort studies at oneyear. Follow-up rates are maximized by central storage of patient identifiers.
\end{abstract}

Keywords: Research collaborative, Surgery, Follow-up, Methodology

Correspondence: dnepogodiev@doctors.org.uk

Academic Department of Surgery, Heritage Building, University of

Birmingham, Birmingham, UK

(c) The Author(s). 2019 Open Access This article is distributed under the terms of the Creative Commons Attribution 4.0 International License (http://creativecommons.org/licenses/by/4.0/), which permits unrestricted use, distribution, and reproduction in any medium, provided you give appropriate credit to the original author(s) and the source, provide a link to the Creative Commons license, and indicate if changes were made. The Creative Commons Public Domain Dedication waiver (http://creativecommons.org/publicdomain/zero/1.0/) applies to the data made available in this article, unless otherwise stated. 


\section{Background}

Trainee research collaboratives (TRCs) have pioneered methods of rapidly delivering high quality, prospective, cross-sectional 'snapshots' of surgical practice and outcomes $[1,2]$. TRC studies are led by frontline clinicians and students, without the need for significant additional infrastructural resources or funding. They capture data over short time periods across multiple centres, collating large datasets [3-5] that can be used to generate hypotheses for future randomised trials and identify targets for national quality improvement [6-10].

TRC studies are delivered by student and postgraduate trainees who rotate between hospitals at least once every 12 months, which would create discontinuity within local teams if studies were run over protracted periods of time. Consequently, most surgical TRC studies follow patients up to the point of discharge or to postoperative day 30; no published observational studies from TRCs have undertaken outcome assessment beyond 6 months [6-10]. In planning longer term follow-up, a particular challenge is ensuring safe local storage of patient identifiers so that patients can be followed-up at one-year even if the original study collaborators at that site have rotated to continue their training at another centre.

Outcomes After Kidney injury in Surgery (OAKS) was the first TRC cohort study to attempt to collect to oneyear follow-up data. The aim of this study was to evaluate one-year follow-up and data completion rates, and to identify factors associated with improved follow-up rates.

\section{Methods}

\section{Student Audit and Research in Surgery (STARSurg)}

Student Audit and Research in Surgery (STARSurg) is the UK's national medical student research collaborative. It is coordinated by a team of medical students and postgraduate trainees. The collaborative model and the educational benefits to participating students have been described previously $[11,12]$. STARSurg studies are delivered by 'mini-teams' at each centre consisting of consultant surgeons, junior doctors and medical students.

\section{Outcomes After Kidney injury in Surgery}

Outcomes After Kidney injury in Surgery (OAKS) [13] is a multicentre study which prospectively identified patients in the UK and Republic of Ireland undergoing major gastrointestinal or liver resection, or reversal of ileostomy or colostomy from 23 September 2015 to 18 November 2015. In the United Kingdom, the South-East Scotland Research Ethics Service (reference: NR/1506AB4) confirmed that ethical review was not required, as this observational study only collected routine, non- patient identifiable data. Individual participating UK centres were responsible for registering the study locally as either clinical audit or service evaluation. In the Republic of Ireland, participating centres were responsible for securing research ethics approval locally, as required by institutional regulations. The 30-day outcomes from the OAKS study have been reported previously $[14,15]$.

Data was collected on the Research Electronic Data Capture (REDCap) system, an online platform for secure web-based data collection. The REDCap platform was developed in 2004 at Vanderbilt University, which is a secure data collection tool meeting the Health Insurance Portability and Accountability Act (HIPAA) compliance standards. Patients' hospital or NHS identification numbers and linked study-specific identification numbers were stored in accordance with local Caldicott Guardian approvals; either centrally on the REDCap system or within an encrypted spreadsheet held securely on the local hospital computer network by a member of the data collection team (a local investigator, supervising consultant, or audit officer).

In the period November 2016 to May 2017 the STAR Surg network collected one-year outcomes for the patients identified in the initial prospective patient enrolment phase of OAKS. Patients were excluded from oneyear follow-up if they had died within 30 days of index surgery, as there would be no additional data to collect from these patients since the 30-day follow-up that had already been completed previously. At centres that had participated in initial OAKS data collection, new miniteams were recruited to complete one-year follow-up. The clinical endpoints collected at one-year were (1) mortality at 1-year, (2) myocardial infarction or cerebrovascular accident at 1-year, (3) total combined hospital length of stay up to 1-year postoperatively, (4) the most recent available serum creatinine value up to 1-year, (5) nephrology review at 1-year, and (6) dialysis at 1-year. These clinical endpoints based on a review of the literature on postoperative AKI [16-19]. In this observational study, clinic follow-up visits and blood tests were arranged by clinical teams according to their normal practice. No additional follow-up visits or blood tests were arranged for this study. Follow-up was considered to have been achieved if patients' records had been successfully reviewed, even if no creatinine tests had been completed by the clinical team during the follow-up period.

Centres were considered to have registered for collection of one-year follow-up if a data collection mini-team was established at the site, institutional approval was granted for collected of follow-up data, and at least one patient was followed-up at the site.

\section{Outcome measures}

The primary outcome for this report was the mortality follow-up rate for mortality. This was the proportion of patients for whom the primary endpoint (mortality) was followed-up at 1-year. The secondary outcome was the 
data completeness rate in centres that registered to collect one-year follow-up. The data completion rate was the proportion of patients with complete data for all six clinical endpoints.

\section{Investigator feedback survey}

Following locking of the OAKS database, an electronic survey was disseminated to all investigators who had participated in one-year follow-up (Additional file 1: Table S1). This assessed investigators' experience of one-year follow-up data collection. 5-point Likert scales were used to assess investigators' experience of the following (from 1 = very difficult, to 5 = very easy): identifying a supervising consultant; registering the audit; linking patient hospital identifier to the study-specific identifier; collecting data using local hospital computer systems, or paper records. For analysis, scores of 4 to 5 out of 5 were categorised as "Positive", and scores of 1 to 3 out of 5 were categorised as "Negative" responses to create a dichotomous variable.

\section{Statistical analysis}

The baseline characteristics of patients lost to follow-up were compared to those patients who were successfully followed-up. Continuous variables were expressed as mean with standard deviation, or median with interquartile range. Continuous variables were analysed using ttest or Mann-Whitney test, where appropriate. Categorical variables were expressed as percentages and analysed using Chi-squared test, or with Fisher's exact modification if expected cell counts were less than five. For all analyses, a $p$-value of $<0.05$ was considered as statistically significant. Data analysis was undertaken using R Foundation Statistical Software (R 3.2.1, R Foundation for Statistical Computing, Vienna, Austria).

\section{Results}

\section{Centre registration}

Of 173 centres that had collected baseline data in the initial phase of OAKS, 126 centres registered to participate in one-year follow-up. Of the 47 centres that did not register, 35 were unable to obtain patient ID link sheets, and 12 were not granted audit and/or Caldicott Guardian approval prior to the data collection deadline (Fig. 1). Centres in Scotland, Ireland, and England all achieved similar levels of registration to participate in one-year follow-up ( $88.9 \%$ vs $78.6 \%$ vs $72.5 \%$ respectively, Table 2), however there were significantly fewer

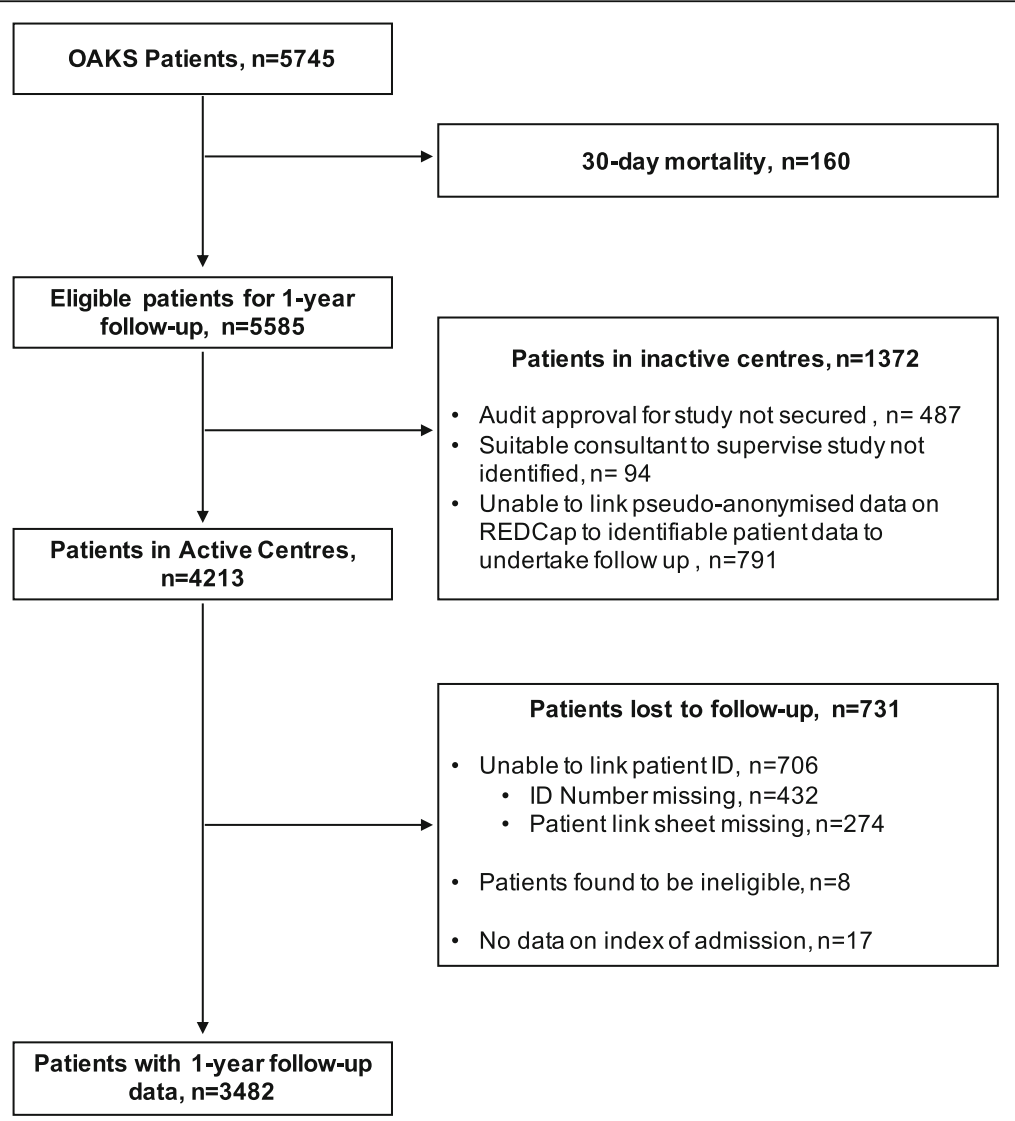

Fig. 1 Flowchart of 1-year follow-up in the OAKS study 
centres in Wales (40.0\%). Centres at which a junior doctor was engaged in the process were more likely to register to enter data $(80.6 \%$ vs $46.2 \%, p<0.001)$. Centres which had stored patient hospital identifiers on the central REDCap system during the initial data collection phase had a significantly higher participation rate in one-year follow-up $(83.6 \%$ vs $67.0 \%, p=0.019)$. However, prior centre participation in STARSurg projects preceding OAKS did not affect the likelihood of centres registering to collect oneyear follow-up ( $74.8 \%$ vs $61.5 \%, p=0.160)$.

\section{Follow-up rates}

The initial data collection phase of OAKS captured 5745 patients, of whom 5585 remained alive at 30days following their index procedure (Fig. 1) and eligible for one-year follow-up. Overall 62.3\% (3482/ 5585 ) of patients were followed-up at 1 year. Of the 2103 patients lost to follow-up, 65.2\% (1372) were from the 47 centres that did not register to participate in one-year follow-up. In registered centres, the follow-up rate was $82.6 \%(3482 / 4213)$.

\section{Characteristics of patients followed-up at one-year}

There were no significant differences in age, American Society of Anaesthesiologists (ASA) grade, Revised Cardiac Risk Index (RCRI), urgency of surgery and contamination between patients with and without follow-up at one-year (Table 1). However, patients who were followed-up had significantly higher rates of open surgery compared to patients that were not followed-up $(61.5 \%$ vs $52.0 \%, p<0.001)$.
There were no significant difference in rates of AKI (12.7\% vs $10.7 \%, p=0.060$ ) between patients with and without one-year follow-up.

\section{Data completeness}

Centre characteristics associated with $\geq 95 \%$ completeness are presented in Table 2. In centres registered to collect 1-year follow-up outcomes, overall data completeness was $83.1 \%$. Of the 126 of centres that participated, $57.9 \%(n=73)$ had $\geq 95 \%$ data completeness. Scotland had significantly more centres with $\geq 95 \%$ data completeness (100.0\%) compared to England, Ireland, and Wales $(55.8 \%$ vs $36.4 \%$ vs $0 \%, p<0.001)$. The more patients a centre had to follow-up, the less likely it was to achieve $\geq 95 \%$ data completeness $(<15: 77.4 \%$ vs 15 29: $59.0 \%$ vs $30-59: 51.4$ vs $>60: 36.8 \%)$. Centres storing patient identifiers on the central REDCap system had significantly higher rates of $\geq 95 \%$ data completeness than those storing identifiers locally $(72.5 \%$ vs $48.0 \%$, respectively, $p<0.001$ ).

\section{Investigator feedback survey}

Survey responses were received from 285 students and junior doctors, a $78 \%(285 / 365)$ response rate. At least one response was received from $86 \%(148 / 173)$ of centres that participated in initial data collection in 2015. Of centres that returned the survey, 59 (40.0\%) had 100\% data completion of one-year follow-up, 72 (48.6\%) had $\geq 95 \%$ data completion and 23 (15.5\%) did not register to submit one-year follow-up data. Table 3 summarises respondent

Table 1 Characteristics of patients with one-year follow-up completed

\begin{tabular}{|c|c|c|c|c|}
\hline & & $\begin{array}{l}\text { No follow-up } \\
(n=2104)\end{array}$ & $\begin{array}{l}\text { Follow-up } \\
(n=3481)\end{array}$ & $\overline{p \text {-value }}$ \\
\hline Age (years) & Mean (SD) & $62.8(15.9)$ & $62.6(16)$ & 0.689 \\
\hline \multirow[t]{2}{*}{ Gender } & Female & $1561(44.8)$ & $967(46.0)$ & 0.417 \\
\hline & Male & $1920(55.2)$ & $1137(54.0)$ & \\
\hline \multirow[t]{2}{*}{ ASA Grade } & ASA I-II & $2176(67.0)$ & $1312(68.5)$ & 0.279 \\
\hline & ASA III-V & $1071(33.0)$ & $604(31.5)$ & \\
\hline \multirow[t]{2}{*}{ Operative urgency } & Elective & $2752(79.1)$ & $1687(80.2)$ & 0.314 \\
\hline & Emergency & $729(20.9)$ & $417(19.8)$ & \\
\hline \multirow[t]{2}{*}{ RCRI score } & $<3$ & $3328(95.7)$ & $2014(96.0)$ & 0.491 \\
\hline & $\geq 3$ & $151(4.3)$ & $83(4.0)$ & \\
\hline \multirow[t]{2}{*}{ Operative approach } & Laparoscopic & $1339(38.5)$ & $1006(48.0)$ & $<0.001$ \\
\hline & Open/ laparoscopic converted to open & $2136(61.5)$ & $1090(52.0)$ & \\
\hline \multirow[t]{2}{*}{ Operative contamination } & Clean-contaminated & $3234(93.2)$ & $1928(91.9)$ & 0.065 \\
\hline & Contaminated & $235(6.8)$ & $170(8.1)$ & \\
\hline \multirow[t]{3}{*}{ AKI within 7 days of index surgery } & No AKI & 2979 (85.6) & $1837(87.3)$ & 0.060 \\
\hline & AKI & $443(12.7)$ & $225(10.7)$ & \\
\hline & Missing & $59(1.7)$ & $42(2.0)$ & \\
\hline
\end{tabular}


Table 2 OAKS centre characteristics, centre activity and data completeness at one-year postoperatively

\begin{tabular}{|c|c|c|c|c|c|c|c|}
\hline & & \multicolumn{3}{|c|}{ Centre active in OAKS } & \multicolumn{3}{|c|}{ Centre $\geq 95 \%$ completeness in OAKS } \\
\hline & & Active $(n=126)$ & Inactive $(n=47)$ & $\overline{p \text {-value }}$ & Yes $(n=73)$ & No $(n=53)$ & $\overline{p \text {-value }}$ \\
\hline \multirow[t]{4}{*}{ UK Countries } & England & $95(72.5)$ & $36(27.5)$ & 0.045 & $53(55.8)$ & $42(44.2)$ & $<0.001$ \\
\hline & Ireland & $11(78.6)$ & $3(21.4)$ & & $4(36.4)$ & $7(63.6)$ & \\
\hline & Scotland & $16(88.9)$ & $2(11.1)$ & & $16(100.0)$ & $0(0.0)$ & \\
\hline & Wales & $4(40.0)$ & $6(60.0)$ & & $0(0.0)$ & $4(100.0)$ & \\
\hline \multirow[t]{4}{*}{ Total number of patients to be followed up } & $<15$ patients & $31(70.5)$ & $13(29.5)$ & 0.491 & $24(77.4)$ & $7(22.6)$ & 0.030 \\
\hline & 15-29 patients & $39(72.2)$ & $15(27.8)$ & & $23(59.0)$ & $16(41.0)$ & \\
\hline & 30-59 patients & $37(69.8)$ & $16(30.2)$ & & $19(51.4)$ & $18(48.6)$ & \\
\hline & $>60$ patients & 19 (86.4) & $3(13.6)$ & & $7(36.8)$ & $12(63.2)$ & \\
\hline Percentage of patients with complete follow-up & Mean (SD) & - & - & - & $28.3(21.6)$ & $27.9(21.9)$ & 0.877 \\
\hline \multirow[t]{2}{*}{ Junior doctor present in OAKS mini-team ${ }^{\mathrm{a}}$} & Yes & $108(80.6)$ & $26(19.4)$ & $<0.001$ & $63(58.3)$ & $45(41.7)$ & 0.825 \\
\hline & No & $18(46.2)$ & $21(53.8)$ & & $10(55.6)$ & $8(44.4)$ & \\
\hline \multirow[t]{2}{*}{ Central storage of patient hospital identifiers } & Yes & $51(83.6)$ & $10(16.4)$ & 0.019 & $37(72.5)$ & $14(27.5)$ & 0.006 \\
\hline & No & $75(67.0)$ & $37(33.0)$ & & $36(48.0)$ & $39(52.0)$ & \\
\hline \multirow[t]{2}{*}{ Survey respondents } & Yes & $125(84.5)$ & $23(15.5)$ & $<0.001$ & $72(57.6)$ & $53(42.4)$ & 0.392 \\
\hline & No & $1(4.0)$ & $24(96.0)$ & & 1 (100.0) & $0(0.0)$ & \\
\hline
\end{tabular}

a Junior doctors are present in each mini-team over a data collection period

characteristics and experience of OAKS-2 by data completeness. Only collaborators with positive experience of linking patient ID were more likely to achieve $>95 \%$ data completeness $(71.6 \%$ vs $37.6 \%, p<0.001)$. There was no association between perceived difficulty with registering audit, data collection, and identifying a supervising consultant, and $>95 \%$ data completeness. Following this study, a summary of recommendations for future multi- centre collaborative studies with longitudinal follow-up were developed and presented in Table 4.

\section{Discussion}

OAKS was the first TRC prospective cohort study to attempt to complete longitudinal one-year follow-up. This report demonstrates that most centres were able to collect one-year follow-up data with high levels of data

Table 3 OAKS collaborator survey responses, centre activity and data completeness at one-year postoperatively

\begin{tabular}{|c|c|c|c|c|}
\hline & & \multicolumn{3}{|c|}{ Respondent at a centre with $\geq 95 \%$ completeness } \\
\hline & & $\overline{Y e s}(n=141)$ & No $(n=111)$ & $p$-value \\
\hline \multirow[t]{3}{*}{ Stage of Training } & Junior Doctor & $47(56.6)$ & $36(43.4)$ & 0.929 \\
\hline & Later Year Student & $52(56.5)$ & $40(43.5)$ & \\
\hline & Early Year Student & $41(53.9)$ & $35(46.1)$ & \\
\hline \multirow[t]{2}{*}{ Previous participation in initial phase of OAKS data collection } & Yes & $66(56.4)$ & $51(43.6)$ & 0.850 \\
\hline & No & $74(55.2)$ & $60(44.8)$ & \\
\hline \multirow[t]{2}{*}{ Prior experience with audit } & Yes & $65(60.2)$ & $43(39.8)$ & 0.222 \\
\hline & No & $75(52.4)$ & $68(47.6)$ & \\
\hline \multirow[t]{2}{*}{ Rating of experience identifying consultant } & Positive (4-5) & $91(58.7)$ & $64(41.3)$ & 0.235 \\
\hline & Not Positive $(<4)$ & $49(51.0)$ & $47(49.0)$ & \\
\hline \multirow[t]{2}{*}{ Rating of experience registering audit ${ }^{a}$} & Positive (4-5) & $67(56.8)$ & $51(43.2)$ & 0.763 \\
\hline & Not Positive $(<4)$ & $73(54.9)$ & $60(45.1)$ & \\
\hline \multirow[t]{2}{*}{ Rating of experience linking Patient ID ${ }^{a}$} & Positive (4-5) & $96(71.6)$ & $38(28.4)$ & $<0.001$ \\
\hline & Not Positive $(<4)$ & $44(37.6)$ & $73(62.4)$ & \\
\hline \multirow[t]{2}{*}{ Rating of experience collecting data ${ }^{a}$} & Positive (4-5) & $106(59.2)$ & $73(40.8)$ & 0.104 \\
\hline & Not Positive $(<4)$ & $34(47.9)$ & $37(52.1)$ & \\
\hline
\end{tabular}

${ }^{\mathrm{a}}$ Rated on a self-reported Likert scale between 1 (very difficult) and 5 (very easy) 
Table 4 Summary of recommendations for future multi-centre collaborative studies with longitudinal follow-up

\begin{tabular}{|c|c|}
\hline Number & $\begin{array}{l}\text { Recommendation to improve completeness of } \\
\text { longitudinal follow-up }\end{array}$ \\
\hline \multicolumn{2}{|c|}{ 1. Study Design Recommendations } \\
\hline 1.1 & $\begin{array}{l}\text { Linked patient identifiers should be kept in a central } \\
\text { repository (for example a REDCap system) if Caldicott } \\
\text { Guardian approval is given to minimise loss to follow-up }\end{array}$ \\
\hline \multicolumn{2}{|c|}{ 2. Study Delivery Recommendations } \\
\hline 2.1 & $\begin{array}{l}\text { Included at least one team member with previous } \\
\text { experience in trainee research collaborative projects } \\
\text { in each data collection team, where possible. }\end{array}$ \\
\hline 2.2 & $\begin{array}{l}\text { Having junior doctors paired to students in data collection } \\
\text { teams improve centre participation and data completeness } \\
\text { rates. Where this is not possible, at least one senior medical } \\
\text { student with previous collaborative audit experience should } \\
\text { be part of the data collection team. }\end{array}$ \\
\hline 2.3 & $\begin{array}{l}\text { A network of regional leads are useful to monitor local } \\
\text { progress and feedback to steering committee }\end{array}$ \\
\hline 2.4 & $\begin{array}{l}\text { Tracking regional variation in performance through the } \\
\text { study and targeting specific efforts to improve follow-up } \\
\text { and data completeness in these areas may increase data } \\
\text { quality and maximise efficiency. }\end{array}$ \\
\hline 2.5 & $\begin{array}{l}\text { In high-volume centres where achieving high data } \\
\text { completeness may be burdensome, consider permitting } \\
\text { involvement additional team members to provide support. }\end{array}$ \\
\hline
\end{tabular}

completeness. Although the overall follow-up rate was only $62 \%$, there was no evidence of systematic bias in patients being followed-up. Factors associated with increased likelihood of achieving $>95 \%$ data completeness were lower numbers of patients to be followed-up, and central storage of patient hospital identifiers. As TRCs have now been set up across Europe [20, 21], validating this methodology will have broad international benefits.

Most studies that complete longitudinal follow-up of prospectively identified patients [22] require patient consent, ethical approval, and significant research infrastructural funding. Even in well resourced, funded trials loss to followup of up to $15 \%$ is expected and built in to sample size calculations [23]. In the UK, National Research Ethics Service regulations permitted collection of one-year outcomes to be completed as clinical audit, without the need for research ethics approval. Without ethical approval it was not possible to collect identifiable data centrally. This report demonstrates that satisfactory follow-up is achievable within this regulatory framework, and without dedicated funding.

The most commonly reported barrier to achieving oneyear follow-up was inability to identify linked patient records. Methods for maintaining linkage between hospital identifiers and study-specific identifiers were either holding hospital identifiers directly on the REDCap system or holding a cross-reference of hospital and study-specific identifiers on hospital computer systems by audit offices or consultants. Collaborating investigators found it easier to complete data collection when approved hospital identifiers were stored on the REDCap system. In Scotland, where national approval was gained for Community Health Index (CHI) identifiers to be stored on REDCap, data completion rates were higher. Therefore, future studies should seek local or national Caldicott guardian approval to store approved hospital identifiers on REDCap.

Loss to follow-up presents a major risk to the internal validity of a study as it leaves a specific population where outcomes remain unassessed, which may differ between groups. In the OAKS study, there were no significant differences in the patient-level demographics, operative indications or ASA grades between the group that underwent one-year follow-up and those that did not. The AKI and mortality rates at 30 -days postoperative follow-up also were not significantly different between the groups that did and did not achieve one-year follow-up data.

A significant limitation to the method of follow-up in this study was its restriction to the hospital where the index surgery was performed. A small number of patients may choose to move their care to another centre, and some patients may be readmitted to a different hospital. Consequently, when patients were followed-up at the index hospital, there may have been no record of readmissions, treatments, and blood tests that took place at other hospitals. In addition, since no specific clinic visits were arranged for this study, if clinical teams did not arrange any postoperative clinic visits, or patients did not attend arranged visits, it is possible that the hospital records that were reviewed as source data for this study may not have been fully accurate.

The evaluation of this study's methodology was limited by the broadness of the barriers explored in the investigator survey. A qualitative approach with detailed interviews with investigators may have been more likely to identify specific difficulties that precluded follow-up from being completed. Incorporating such a qualitative component to future studies may improve follow-up by identifying more solutions [24].

\section{Conclusion}

The OAKS study has demonstrated that prospective TRC cohort studies can successfully complete one-year longitudinal follow-up, with acceptable data completeness rates. Future studies may maximise follow-up rates by optimising procedures for storage of patient identifiers, embedding collaborators with previous experience of TRC studies within data collection team, and tracking regional variation in performance throughout the study.

\section{Supplementary information}

Supplementary information accompanies this paper at https://doi.org/10. 1186/s12874-019-0857-y.

Additional file 1: Table S1. OAKS collaborator survey responses, centre activity and data completeness at one-year postoperatively. 


\section{Abbreviations}

AKI: Acute Kidney Injury; ASA: American Society of Anaesthesiologists; CHI: Community Health Index; OAKS: Outcomes After Kidney injury in Surgery; RCRI: Revised Cardiac Risk Index; REDCap: Research Electronic Data Capture; STARSurg: Student Audit and Research in Surgery; TRCs: Trainee research collaboratives

\section{Acknowledgements}

Not applicable.

\section{Authors' contributions}

JCG, AB, JB. TMD, SKK, KMM, MFB, HAC, BG, MM, PD, CK, HJ, LM, EW, CK, JEF, $E M H, A B, D N, N A, S B, F D, J H, T D P, J P, T R$, and MT conceptualised the study. $J C G, A B, J B$. TMD, SKK, KMM, MFB, HAC, BG, MM, PD, CK, HJ, LM, EW, CK, JEF, $\mathrm{EMH}, \mathrm{AB}$, and $\mathrm{DN}$ coordinated the study nationally. All listed collaborators collected data. SKK and KMM analysed the data. SKK, KMM, AB, TMD, EW, CK, $J E F, E M H, A B, D N$, and JCG drafted the manuscript. All authors contributed to critically revising the manuscript and have approved the final manuscript.

\section{Funding}

Not applicable.

\section{Availability of data and materials}

The datasets used and/or analysed during the current study are available from the corresponding author on reasonable request.

\section{Ethics approval and consent to participate}

Ethics approval was sought from the South-East Scotland Research Ethics Service. Since OAKS was an audit limited to data obtained as part of usual care, NHS ethical review was not required. Patient consent for this study was not applicable.

\section{Consent for publication}

Not applicable.

\section{Competing interests}

The authors declare that they have no competing interests.

Received: 16 August 2018 Accepted: 23 October 2019

Published online: 12 December 2019

\section{References}

1. Horton R. Surgical research or comic opera: questions, but few answers. Lancet. 1996;347(9007):984-5

2. Howes N, Chagla L, Thorpe M, McCulloch P. Surgical practice is evidence based. Br J Surg. 1997;84(9):1220-3.

3. Bhangu A, Kolias AG, Pinkney T, Hall NJ, Fitzgerald JE. Surgical research collaboratives in the UK. Lancet. 2013;382(9898):1091-2.

4. Jamjoom AA, Phan PN, Hutchinson PJ, Kolias AG. Surgical trainee research collaboratives in the UK: an observational study of research activity and publication productivity. BMJ Open. 2016;6(2):e010374.

5. Nepogodiev D, Chapman SJ, Kolias AG, Fitzgerald JE, Lee M, Blencowe NS. The effect of trainee research collaboratives in the UK. Lancet Gastroenterol Hepatol. 2017:2(4):247-8

6. National Surgical Research Collaborative. Multicentre observational study of performance variation in provision and outcome of emergency appendicectomy. Br J Surg. 2013;100(9):1240-52.

7. UK National Surgical Research Collaborative, Blencowe NS, Strong S, Blazeby J, Daniels R, Peden C, Lim J, Messenger D, Stark H, Richards S, Rogers C. Multicentre observational study of adherence to Sepsis Six guidelines in emergency general surgery. Br J Surg. 2017;104(2):e165-71.

8. International Surgical Outcomes Study group. Global patient outcomes after elective surgery: prospective cohort study in 27 low-, middle- and highincome countries. Br J Anaesth. 2016;117(5):601-9.

9. GlobalSurg Collaborative. Mortality of emergency abdominal surgery in high-, middle- and low-income countries. Br J Surg. 2016;103(8):971-88.

10. 2015 European Society of Coloproctology Collaborating Group. The impact of stapling technique and surgeon specialism on anastomotic failure after right-sided colorectal resection: an international multicentre, prospective audit. Colorectal Dis. 2018;20(11):1028-40.
11. Bhangu A, Fitzgerald JE, Kolias AG. Trainee-led research collaboratives: a novel model for delivering multi-Centre studies. ANZ J Surg. 2014;84(12): 902-3.

12. Chapman SJ, Glasbey JC, Khatri C, Kelly M, Nepogodiev D, Bhangu A, Fitzgerald JE. Promoting research and audit at medical school: evaluating the educational impact of participation in a student-led national collaborative study. BMC Med Educ. 2015;15:47.

13. STARSurg Collaborative. Outcomes After Kidney injury in Surgery (OAKS): protocol for a multicentre, observational cohort study of acute kidney injury following major gastrointestinal and liver surgery. BMJ Open. 2016;6(1): e009812.

14. Collaborative S. Prognostic model to predict postoperative acute kidney injury in patients undergoing major gastrointestinal surgery based on a national prospective observational cohort study. BJS Open. 2018;2(6):400-10.

15. Collaborative ST. Association between peri-operative angiotensin-converting enzyme inhibitors and angiotensin-2 receptor blockers and acute kidney injury in major elective non-cardiac surgery: a multicentre, prospective cohort study. Anaesthesia. 2018;73(10):1214-22.

16. Li L, Lau KS, Ramanathan V, Orcutt ST, Sansgiry S, Albo D, Berger DH, Anaya DA. lleostomy creation in colorectal cancer surgery: risk of acute kidney injury and chronic kidney disease. J Surg Res. 2017;210:204-12.

17. O'Connor ME, Hewson RW, Kirwan CJ, Ackland GL, Pearse RM, Prowle JR. Acute kidney injury and mortality 1 year after major non-cardiac surgery. $\mathrm{Br}$ J Surg. 2017;104(7):868-76.

18. Zhu M, Li Y, Xia Q, Wang S, Qiu Y, Che M, Dai H, Qian J, Ni Z, Axelsson J, et al. Strong impact of acute kidney injury on survival after liver transplantation. Transplant Proc. 2010;42(9):3634-8.

19. Wu HC, Wang WJ, Chen YW, Chen HH. The association between the duration of postoperative acute kidney injury and in-hospital mortality in critically ill patients after non-cardiac surgery: an observational cohort study. Ren Fail. 2015:37(6):985-93.

20. Chapman SJ, EuroSurg C. Ileus management international (IMAGINE): protocol for a multicentre, observational study of ileus after colorectal surgery. Color Dis. 2018;20(1):017-25.

21. Pata F, Pellino G. Italian surgical research G: ItSURG: a challenge for surgical research in Italy. Updat Surg. 2017;69(4):551-2.

22. Burbach JP, Kurk SA, van den Braak RR C, Dik VK, May AM, Meijer GA, Punt CJ, Vink GR, Los M, Hoogerbrugge N, et al. Prospective Dutch colorectal cancer cohort: an infrastructure for long-term observational, prognostic, predictive and (randomized) intervention research. Acta Oncol. 2016;55(11): 1273-80.

23. Peterson JC, Pirraglia PA, Wells MT, Charlson ME. Attrition in longitudinal randomized controlled trials: home visits make a difference. BMC Med Res Methodol. 2012:12:178

24. O'Cathain A, Thomas KJ, Drabble SJ, Rudolph A, Hewison J. What can qualitative research do for randomised controlled trials? A systematic mapping review. BMJ Open. 2013;3(6).

\section{Publisher's Note}

Springer Nature remains neutral with regard to jurisdictional claims in published maps and institutional affiliations.

Ready to submit your research? Choose BMC and benefit from:

- fast, convenient online submission

- thorough peer review by experienced researchers in your field

- rapid publication on acceptance

- support for research data, including large and complex data types

- gold Open Access which fosters wider collaboration and increased citations

- maximum visibility for your research: over $100 \mathrm{M}$ website views per year

At BMC, research is always in progress.

Learn more biomedcentral.com/submissions 